Linfocintilografia pré e pós-fisioterapia vascular em pacientes com linfedema.

Autora: Silvia Bacelar.

Orientadora: Lea Mirian Barbosa da Fonseca.

Tese de Mestrado. UFRJ, 2000.

A fisioterapia complexa descongestiva vem sendo a terapia de eleição em tratamento dos linfedemas há alguns anos, tendo sido inicialmente descrita pelo $\mathrm{Dr}$. Foldi, e posteriormente modificada por diversos pesquisadores.

Embora haja diversos métodos de avaliação do edema e dos resultados de tratamentos (perimetria, volumetria, tonometria), a linfocintilografia aparece como opção única no estudo da função linfática, tornando viável tanto o estadiamento linfático pré-tratamento, com estudo de vias, linfonodos e fluxo, quanto as avaliações pós-tratamento, de forma eficaz, não invasiva e sem morbidade.

Este estudo teve como objetivos avaliar a linfocintilografia e a técnica de fisioterapia vascular realizada como formas eficazes de estadiamento linfático e redução de linfedemas. Realizamos linfo- cintilografia pré e pós-tratamento em 22 pacientes com linfedemas primários e secundários a traumas, cirurgias oncológicas, tromboses venosas ou infecções, baseados em critérios clínicos e medidas clássicas indicadoras de melhora do linfedema.

A linfocintilografia mostrou-se um método simples e eficaz para a avaliação da função linfática em pacientes com linfedema, e a técnica de fisioterapia adotada obteve excelentes resultados.

\section{Tratamento endovascular da oclusão das} artérias ilíacas.

Autor: Cleoni Pedron.

Orientadora: Lea Mirian Barbosa da Fonseca.

Tese de Mestrado. UFRJ, 2000.

A oclusão das artérias ilíacas é uma patologia freqüente, com apresentação clínica variável, desde claudicação intermitente até isquemia crítica dos membros inferiores (lesão necrótica).

Os pacientes, geralmente, têm doença aterosclerótica multifocal, com envolvimento de outras partes do sistema cir- culatório. Em conseqüência, o risco cirúrgico alto é usual nesses pacientes.

Várias alternativas cirúrgicas são possíveis para o tratamento de oclusão das artérias ilíacas, com resultados a longo prazo muito bons. A ponte aorto-bifemoral é considerada o tratamento ideal para essas lesões.

Com o desenvolvimento da cirurgia endovascular, foi realizada, em 1979, a primeira recanalização da artéria ilíaca.

O uso de procedimentos pouco invasivos beneficia em muito os doentes de alto risco. $\mathrm{O}$ método de recanalização das artérias ilíacas apresenta, hoje, alta taxa de sucesso, com baixo índice de complicações.

A taxa de sucesso técnico imediato na recanalização das artérias ilíacas está situada entre $80 \%$ e $98 \%$ e mortalidade menor que $0,1 \%$, segundo refere a literatura mundial.

Os bons resultados com a recanalização e implante de "stent" nas oclusões das artérias ilíacas, com baixas morbidade e mortalidade, sugere a inclusão desse procedimento no arsenal terapêutico do cirurgião vascular. 